\title{
A Study on the Narrative Type and Construction Mechanism of Cultural and Creative District
}

\author{
Fang Xie \\ Chongqing University of Technology \\ Chongqing, China
}

\begin{abstract}
With the development of tourism and tourism industry, people are more and more dissatisfied with the tourism products at that time. The development of cultural and creative blocks has brought new tourism direction or destination for the tourists. Many scholars are more and more comprehensive in the research of cultural and creative block, but there is little research on the narrative of cultural and creative block. Taking the pictures of 22 cultural and creative blocks as an example, this paper studies the narrative types and construction mechanism of cultural and creative blocks, and concludes that the current narrative types of cultural and creative blocks mostly focus on nostalgia, which still has a great space for the future development of cultural and creative blocks.
\end{abstract}

Keywords-cultural and creative blocks; narrative; construction mechanism; nostalgia

\section{INTRODUCTION}

With the changes of science and technology and the times in China, the development of tourism is becoming better and better. People's consumption concept gradually changed, and began to pay more attention to cultural consumption. At this time, cultural and Creative Park entered the vision of tourists.

Nowadays, there is no unified definition of cultural and creative industry park at home and abroad. There are many kinds of names of cultural and Creative Park, such as cultural and creative block, cultural industry park, cultural and creative block, historical and cultural block, old block, urban old block and so on. There are many kinds of cultural and creative blocks in this paper, such as the cultural and creative park transformed from the old industrial zone, the new generation of cultural and Art Zone, and the cultural and creative products gathering and entrepreneurship Park.

In recent years, there are many researches on cultural and creative block. Chen Hanxin analyzed the general situation of cultural and creative industries in China at that time, and came to the conclusion that to develop the cultural and creative industries in China healthily, it is necessary to pay attention to talents, respect intellectual property rights and cultivate innovation consciousness [1]. From the perspective of "one-stop experience", Zheng bin, Liu Jiaming and Yang Zhaoping summed up the existing mainstream mode of cultural tourism creative industry park development, and put forward the development countermeasures of cultural tourism creative industry park from the perspective of tourism destination construction[2].By analyzing the spatial distribution characteristics and formation mechanism of Shanghai Creative Industry Cluster Park, Chu Jinfeng studies the temporal and spatial change law of Shanghai Creative Industry Cluster and reflects the development path of Shanghai creative industry[3]. Based on the analysis of Hunan Cultural and Creative Industry Park, Wang Yi and Liao Zhuoxian put forward six feasible path suggestions for upgrading the cultural industry park [4].

In the same way, narrative research is also a lot in media, communication, art, literature and other professional research. For example, Liang Jiasheng and Dong Yuhong expressed their aesthetic views on folk standpoint based on Folk Narrative [5]. Jing Wendong interprets the two novels, the invisibility cloak and the temple of the moon from the perspective of fate narration [6]. However, there are few studies on the narrative types of cultural and creative blocks.

From the perspective of narrative, this paper analyzes the pictures of cultural and creative blocks, so as to analyze the narrative types and construction mechanism of cultural and creative blocks.

\section{RESEARCH METHOD}

\section{A. Visualization Method}

1) Visualization method: The visualization method is used to explore the construction of social reality through some visual forms, such as video, photo, painting, chart, map or other visual forms [7] [8] [9]. In the definition of visual research method, architectural landscape and natural landscape as well as printing and network media are defined as the symbolic environment to convey any number of denotative (literal) and connotative (implied) meanings[10] [11]. In tourism research, many methods can be used to determine the characteristics of a place or multiple places [12], Quantitative and interpretative methods, such as psychoanalysis, discourse analysis, content analysis, semiotics analysis, psychoanalysis or other visual analysis methods, are either alone or combined [10][11] can be used to explore the characteristics of tourism destinations or to understand the visual forms in some publishing media[13]. In the past tourism research, the visual expression "type" in 
(cultural and creative block name) search to find more images of cultural and creative blocks. Using keyword search and search engine is a typical search method [19], which is mainly used to find online research data for tourism research.

After the basic investigation, it was decided to classify the main visual attractions of cultural and creative blocks into nine categories, including shops, sculpture technology, buildings, street devices, wall tiles, commodity painting, roadways, leisure activities and signs. To find the images of cultural and creative blocks based on these nine types of visual attractors, because these nine categories are obviously the main representatives related to cultural and creative blocks, which can better reflect the characteristics and characteristics of cultural and creative blocks.

Finally, a total of 3880 pictures were collected from 280 websites, and 1980 valid pictures were obtained by eliminating the pictures that did not meet the requirements of cultural and creative block categories. There are 10 pictures in each category and 90 pictures in each cultural and creative block.

\section{Research Process}

1) Picture preparation: All the pictures were scrambled so that the subjects could not know the origin of the pictures, but the pictures of each block would be put in a folder.

Please randomly select different kinds of pictures for each of the descriptors. Each of them will select 5 pictures to cover the icons of cultural and creative blocks or related words on the pictures, so that the descriptors can only see the subject part of the pictures. For example, the pictures of sculpture technology only show the part of sculpture technology, so as to avoid the preconceptions of the descriptors. Read.

For each type, 220 pictures (10 pictures for each cultural and creative block) will be prepared, and each picture will be numbered for subsequent statistics. The number of pictures in each type is $1-220$.

2) Describe people's choice: In order to ensure the objectivity of the evaluation, a total of 99 people were selected as descriptors, including 90 college students and 9 teachers. Describe the sex ratio, age distribution and the number of pictures read by each person, as shown in "Table I": specific or comprehensive basic data only according to the research needs [33]. Through field research and online search engine, researchers conducted online keyword

TABLE I. DESCRIPTORS SELECTION TABLE

\begin{tabular}{|l|l|l|l|l|}
\hline \multicolumn{2}{|c|}{ Category } & \multicolumn{2}{c|}{ College student } & \multicolumn{2}{c|}{ teacher } \\
\hline \multirow{2}{*}{ Sex ratio } & male & female & male & female \\
\cline { 2 - 5 } & 40 & 50 & 6 & 3 \\
\hline Age distribution (years) & $18-25$ & $30-50$ & \\
\hline Number of pictures read per person & 20 & 20 & \\
\hline
\end{tabular}

3) Perceptual description: Ask each subject to say three descriptive words (noun or adjective) for each picture according to their first intuition or first impression, such as "nostalgic, scary, industrial style" and other words (do not give words to be chosen by the subject, but describe the real feelings of people). At the end of every 20 pictures, the 20 
After many experiments, 5940 valid words were obtained.

pictures will be put into another folder to avoid the possibility of being selected repeatedly.
"Table II" is a screenshot of some words:

TABLE II. LIST OF VALID WORDS (PART)

\begin{tabular}{|c|c|c|c|c|c|c|c|c|c|}
\hline \multicolumn{4}{|c|}{ 1.shop } & \multicolumn{3}{|c|}{ 2.Sculpture technology } & \multicolumn{3}{|c|}{ 3.Architecture } \\
\hline 1 & European style & Cartoon & romantic & 1 & serious & earnest & team & 1 & \\
\hline 2 & Christmas & Comfortable & Cozy & 2 & strange & leisurely and carefree & Free and easy & 2 & Originality \\
\hline 3 & fresh & beautiful & like & 3 & Sense of weight & Sense of the times & Relaxed & 3 & sense of modernity \\
\hline 4 & Restoring ancient ways & Cold and cheerless & grace & 4 & Meticulous & Hard & Industrial wind & 4 & Restoring ancient ways \\
\hline 5 & Adorable & Comfortable & Lovely & 5 & Dilapidated & Disgraceful & strange & 5 & obsolete \\
\hline 6 & Dilapidated & Boring & Dim & 6 & Restoring ancient ways & Art & Nostalgia & 6 & complex \\
\hline 7 & Restoring ancient ways & Restoring ancient ways & Originality & 7 & Lovely & funny & Music & 7 & sense of modernity \\
\hline 8 & sense of modernity & Western style & Young people & 8 & Restoring ancient ways & rust & lively & 8 & Industrial wind \\
\hline 9 & chaos & innovate & resource utilization & 9 & Strange & Grotesque & abstract & 9 & Industrial wind \\
\hline 10 & Restoring ancient ways & Life & Sentiment & 10 & Personal independence of conduct & Faith & Rock & 10 & Dilapidated \\
\hline 11 & leisure & warm & Originality & 11 & vent & labour & Resign oneself to one's fate & 11 & Interesting \\
\hline 12 & small & regular & Restoring ancient ways & 12 & Art & distinct & Fear & 12 & Industrial wind \\
\hline 13 & Age sense & Color collision & old and worn-out & 13 & fashion & Art & Lovely & 13 & Dilapidated \\
\hline 14 & Leisure time & Relaxed & Interesting & 14 & Art & Humor & distinct & 14 & sense of modernity \\
\hline 15 & old and worn-out & Artistic sense & Gloomy & 15 & nausea & Disorder & monotonous & 15 & neat \\
\hline 16 & Restoring ancient ways & style & atmosphere & 16 & justice & simple & Rural & 16 & Rules \\
\hline 17 & Simplicity & Cold and cheerless & concise & 17 & Dark tone & Rugged & ordinary & 17 & Magical \\
\hline 18 & Restoring ancient ways & Nostalgia & Low-key & 18 & abstract & concise & Do not understand & 18 & Dilapidated \\
\hline 19 & Unique & Art & like & 19 & vivid & absolutely lifelike & Crowding & 19 & strange \\
\hline 20 & Originality & distinct & environmental protection & 20 & texture & Lovely & sexy & 20 & Rusty \\
\hline 21 & pink & girl & youth & 21 & Pain & Life & greasy & 21 & Restoring ancient ways \\
\hline
\end{tabular}

\section{Semantic Analysis and Classification}

1) Classification of descriptors of visual attraction in cultural and creative district: 5940 words obtained from the experiment were summarized by category according to the serial number. Words with the same meaning or similar meaning are replaced by one word, such as nostalgia, sense of history, sense of time, retro and other words are used to refer to nostalgia, quiet, quiet and other words are used to refer to quiet.

The description and classification results are as shown in "Table III":

TABLE III. ClASSIFICATION OF DESCRIPTIVE WORDS (PART)

\begin{tabular}{|c|c|c|c|c|}
\hline \multirow[t]{2}{*}{1} & \multicolumn{2}{|r|}{ 1.Shop } & \multicolumn{2}{|r|}{ 2.Sculpture technology } \\
\hline & Originality 9 & innovate $8 /$ novel & $\begin{array}{l}\text { Originalit } \\
\quad \text { y } 13\end{array}$ & Originality12/innovate2/novel \\
\hline 3 & Nostalgia 75 & $\begin{array}{l}\text { Restoring ancient ways } 21 / \text { Age sense } 13 / \text { tradition } 8 / \text { Nostalgia } \\
8 / \text { Sense of history } 7 / \text { classical } 4 / \text { To fake something } \\
\text { antique/ancient /Having an antique flavour /archaic rhyme } \\
\text { /Primitive simplicity } 10\end{array}$ & Life 22 & $\begin{array}{l}\text { Life 6/Home Furnishing /warm6/Have love3/real4/Feeling/Care } \\
\text { for }\end{array}$ \\
\hline 4 & Special 27 & $\begin{array}{l}\text { Special6/characteristic4/unique3/unique2/ peculiar2/Have } \\
\text { style6/Out of the ordinary/Have ideas/different styles } \\
\text { /characteristic }\end{array}$ & Special 15 & $\begin{array}{l}\text { Special2/characteristic5/Have great originality2/Personal } \\
\text { independence of conduct/unique/Characteristic/Totally different } \\
\text { /Different in manner /unique }\end{array}$ \\
\hline 5 & Leisure time 29 & $\begin{array}{l}\text { Leisure time6/Leisurely and } \\
\text { carefree9/Relax5/Relaxed4/free/comfortable/leisure/Leisure } \\
\text { /Holiday }\end{array}$ & $\begin{array}{l}\text { Care for } \\
20\end{array}$ & Ugly7/Disgraceful4/Ugly/Care for/rough7 \\
\hline 6 & Cozy 35 & Cozy14/Comfortable16/comfortable5 & $\begin{array}{l}\text { great } \\
\text { momentu } \\
\mathrm{m} 15\end{array}$ & $\begin{array}{l}\text { great momentum3/Free and easy3/Unruly2/Imposing } \\
\text { manner/Rugged/Domineering/momentum /Bold and } \\
\text { unconstrained /Heroic /Rivers and lakes }\end{array}$ \\
\hline 7 & Industrial wind 5 & Industrial wind 5 & $\begin{array}{l}\text { Nostalgia } \\
38\end{array}$ & $\begin{array}{l}\text { Restoring ancient ways } 9 / \text { Age sense } 7 / \text { tradition6/Nostalgia4Sense } \\
\text { of history3/Antiquity } 2 \text { /inherit } 2 \text { /History /Primitive simplicity } 4\end{array}$ \\
\hline
\end{tabular}

2) Frequency analysis of descriptors: The word frequency of each type of descriptors of different types of visual attractors is counted, and the word frequency table of visual experience of cultural and creative block is obtained ("Table IV"). 


\begin{tabular}{|c|c|c|c|}
\hline \multicolumn{2}{|c|}{ 2. Sculpture } & \multicolumn{2}{|c|}{ 3. Architecture } \\
\hline Nostalgia38 & 38 & Nostalgia100 & 100 \\
\hline vivid35 & 35 & great momentum 38 & 38 \\
\hline Life 22 & 22 & modern33 & 33 \\
\hline Interesting21 & 21 & commonly 31 & 31 \\
\hline ug1y20 & 20 & Special27 & 27 \\
\hline Lovely18 & 18 & obsolete 25 & 25 \\
\hline Good-1ooking17 & 17 & neat22 & 22 \\
\hline abstract 17 & 17 & Industrial wind22 & 22 \\
\hline strange16 & 16 & simple18 & 18 \\
\hline Special15 & 15 & Good-1ooking 17 & 17 \\
\hline great momentum15 & 15 & Western style14 & 14 \\
\hline Art14 & 14 & Cozy 14 & 14 \\
\hline Frightening14 & 14 & Life 14 & 14 \\
\hline Originality 13 & 13 & Elegant12 & 12 \\
\hline Industrial wind12 & 12 & Cold and cheerless 12 & 12 \\
\hline
\end{tabular}

\begin{tabular}{|c|c|}
\hline \multicolumn{2}{|c|}{ 4. Street device } \\
\hline Nostalgia68 & 68 \\
\hline industrialization48 & 48 \\
\hline 0riginality36 & 36 \\
\hline distinct27 & 27 \\
\hline Specia126 & 26 \\
\hline Colorfu125 & 25 \\
\hline Interesting16 & 16 \\
\hline Art15 & 15 \\
\hline literature15 & 15 \\
\hline Life 14 & 14 \\
\hline common1y14 & 14 \\
\hline Tal1 and big12 & 12 \\
\hline strange12 & 12 \\
\hline obsolete11 & 11 \\
\hline abstract11 & 11 \\
\hline
\end{tabular}

\begin{tabular}{|c|c|}
\multicolumn{2}{|c|}{ 5. Wal1 tile } \\
\hline Nostalgia92 & 92 \\
\hline obsolete59 & 59 \\
\hline Special25 & 25 \\
\hline 1iterature25 & \\
\hline Art24 & 25 \\
\hline commonly20 & 24 \\
\hline Originality19 & 19 \\
\hline vitality18 & 18 \\
\hline Colorful17 & 17 \\
\hline Good-looking15 & 15 \\
\hline neat15 & 15 \\
\hline monotonous13 & 13 \\
\hline modern12 & 12 \\
\hline great & \\
\hline momentum12 & 12 \\
\hline simple11 & 11 \\
\hline
\end{tabular}

\section{RESULT ANALYSIS}

All word frequencies are collected in one table, and according to different research needs, different kinds of statistics can be made, thus different research results can be obtained. Each kind of classification will get a different word frequency record. However, from the word frequency record obtained, we can see that no matter according to the classification and induction of visual attractors or according to the classification and induction of cultural and creative blocks, there are always several particularly obvious characteristic words in the first place.

\section{A. Classification by Block}

In this paper, we collect 22 pictures of cultural and creative blocks and the description words of pictures. Through the description results of the descriptors, we get the word frequency of pictures of all cultural and creative blocks. From the word frequency table of cultural and creative block, we can see that the word frequency of each visual attraction in 22 cultural and creative blocks is different. From the first cultural and creative block to the 22nd cultural and creative block, the high frequency of word frequency can be seen at a glance.

TABLE V. 22 BLOCK WORD FREQUENCY TABLE(PART)

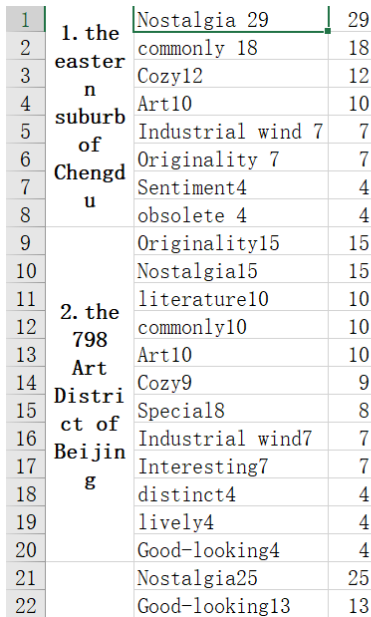

The "Table V" is part of the chart of word frequency in 22 cultural and creative districts. Because many words only appear once, only the word frequency classification with high number of word frequency is sorted out. Through sorting out the word frequency table, we can get the word frequency number of each cultural and creative block. In the eastern suburb of Chengdu, the number of words with high frequency is nostalgia, general, warmth and art; in the 798

\begin{tabular}{|c|c|c|c|c|c|}
\hline \multirow{9}{*}{$\begin{array}{l}\text { 7. Tia } \\
\text { njin } \\
\text { Mians } \\
\text { an }\end{array}$} & Nostalgia20 & 20 & \multirow{2}{*}{\multicolumn{2}{|c|}{\begin{tabular}{c|c} 
10. Yu Nostalgia41 \\
nnan Special13
\end{tabular}}} & \\
\hline & commonly19 & 19 & & & \\
\hline & Speciall1 & 11 & Lijia & Colorful9 & \\
\hline & Industrial wind8 & 8 & ng & Leisure time7 & \\
\hline & Interesting6 & 6 & Dayan & Good-1ooking6 & \\
\hline & Originality5 & 5 & Huaxi & Sentiment4 & \\
\hline & spacious5 & 5 & ang & Cheerful4 & \\
\hline & Frightening4 & 4 & & Nostalgia22 & \\
\hline & neat4 & 4 & & commonly17 & \\
\hline & commonly13 & 13 & & Special8 & \\
\hline & Speciallo & 10 & & sense of modernity 8 & \\
\hline & Nostalgia9 & 9 & 11. th & simple6 & \\
\hline & style7 & 7 & e old & distinct5 & \\
\hline & Originality7 & 7 & facto & Cozy5 & \\
\hline 8. Sha & Colorful6 & 6 & ry of & quiet5 & \\
\hline nghai & Leisure time6 & 6 & $X i^{\prime}$ an & Cold and cheerless 4 & \\
\hline Hongf & Comfort6 & 6 & & obsolete4 & \\
\hline ang & 1iterature6 & 6 & & literature4 & \\
\hline & simple6 & 6 & & Frightening4 & \\
\hline & Cozy5 & 5 & & Industrial wind4 & \\
\hline & Elegant5 & 5 & & Nostalgia30 & \\
\hline & To make clear4 & 4 & & obsolete8 & \\
\hline
\end{tabular}

Art District of Beijing, the number of words with high frequency is creativity, nostalgia, literature and art; in Wuhan 824 , the number of words with high frequency is nostalgia, good looking, warmth and creativity; in Tianzifang of Shanghai, the number of words with high frequency is nostalgia, literature and art. Art, good-looking, special; The high frequency of Shanghai M50 is general, nostalgic, elegant and interesting; the high frequency of Chongqing 
nostalgic. Shenyang Tiexi 1905 has a high number of word frequencies: nostalgia, industrial style, creativity, and special; The word frequency of Guangdong tit creative park is higher: nostalgia, quiet, leisure, fashion; the word frequency of Guangdong Yangcheng creative park is higher: simple, general, nostalgia, clear; the word frequency of Guangdong 1850 creative park is higher: nostalgia, special, leisure, art; the word frequency of Xi'an Banpo International Art Zone is higher: nostalgia, antiquity, art, harmony.

The word frequency order of each visual attraction may be different, but the word frequency occupying high frequency mainly includes nostalgia, creativity and literature and art.

\section{B. Classification by Visual Attraction}

There are nine categories of visual attractors. According to the classification of visual attractors, the number of word frequencies is sorted, as shown in "Table VI": is nostalgic, general, obsolete and atmospheric; the high frequency of words in Shanghai old wharf is distinctive and

TABLE VI. VIsUAL ATtRactor ClassificATION WORD FREQUENCY TABLE (PART)

\begin{tabular}{c|c|c}
\multirow{1}{*}{1} & \multicolumn{2}{|c}{ 1. Shop } \\
\cline { 2 - 3 } 2 & Nostalgia75 & 75 \\
\cline { 2 - 3 } 3 & Cozy35 & 35 \\
\hline 4 & Sentiment34 & 34 \\
\hline 5 & literature33 & \\
\hline 6 & Leisure time29 & 29 \\
\hline 7 & Specia127 & 27 \\
\hline 8 & quiet20 & \\
\hline 8 & commonly17 & 17 \\
\hline 10 & Comfort17 & 17 \\
\hline 11 & Life 17 & 17 \\
\hline 12 & modern16 & \\
\hline 13 & Elegant16 & 16 \\
\hline 14 & dark14 & \\
\hline 15 & Simplicity12 & 12 \\
\hline 16 & obsolete12 & 12 \\
\hline
\end{tabular}

As shown in "Table VI", there are nine categories of visual attractors. The word frequency of each visual attractor is arranged in the order of more to less. It can be seen from the figure that the word frequency of the visual attractor of the shop is higher: nostalgia, warmth, sentiment, literature and art; the word frequency of the visual attractor of sculpture technology is higher: nostalgia, vividness, Life, fun; the word frequency of architectural visual attraction is higher: nostalgia, atmosphere, modern, general; the word frequency of street device visual attraction is higher: nostalgia, industrialization, creativity, bright; the word frequency of wall brick visual attraction is higher: nostalgia, old, special, literature and art; commodity The frequency of words with high number of color painting visual attractors are nostalgia, general, good-looking and interesting; the frequency of words with high number of lane visual attractors are general, nostalgia, quiet and lonely; the frequency of words with high number of leisure activities visual attractors are leisure, ease, joy and interesting; the frequency of words with high number

\section{Street device}

\begin{tabular}{|c|c|}
\hline Nostalgia68 & 68 \\
\hline industrialization48 & 48 \\
\hline Originality36 & 36 \\
\hline distinct27 & 27 \\
\hline Specia126 & 26 \\
\hline Colorful25 & 25 \\
\hline Interesting16 & 16 \\
\hline Art15 & 15 \\
\hline 1iterature15 & 15 \\
\hline Life 14 & 14 \\
\hline commonly14 & 14 \\
\hline Ta11 and big12 & 12 \\
\hline strange12 & 12 \\
\hline obsolete11 & 11 \\
\hline abstract11 & 11 \\
\hline
\end{tabular}

\begin{tabular}{c|c}
\hline \multicolumn{2}{|c}{ 5. Wall tile } \\
\hline Nostalgia92 & 92 \\
\hline obsolete59 & 59 \\
\hline Special25 & 25 \\
\hline literature25 & 25 \\
\hline Art24 & 24 \\
\hline commonly20 & 20 \\
\hline Originality19 & 19 \\
\hline vitality18 & 18 \\
\hline Colorful17 & 17 \\
\hline Good-looking15 & 15 \\
\hline neat15 & 15 \\
\hline monotonous13 & 13 \\
\hline modern12 & 12 \\
\hline great & \\
momentum12 & 12 \\
simple11 & 11
\end{tabular}

of signboard visual attractors The high number of words are: distinctive, special, general, nostalgic.

\section{Classification According to the Visual Attraction of the Block}

Each block contains nine kinds of visual attractions, and the table of word frequency is also sorted out. 
TABLE VII. Word Frequency TABle of Visual Attraction of Cultural AND CREATiVe Block (PART)

\begin{tabular}{|c|c|c|c|c|c|c|c|}
\hline 1 & & & & & & & 1. the easte \\
\hline 2 & & & & 1. Shop & & & \\
\hline 3 & Originality2 & Nostalgia2 & 1iterature 3 & Lovely2 & Cozy3 & Sentiment2 & 20 ther 16 \\
\hline 4 & $\begin{array}{l}\text { Originality/ } \\
\text { innovate }\end{array}$ & $\begin{array}{l}\text { Restoring } \\
\text { ancient } \\
\text { ways2 }\end{array}$ & $\begin{array}{l}\text { literature } \\
\text { /fresh }\end{array}$ & $\begin{array}{l}2 \text { Lovely/Ado } \\
\text { rable }\end{array}$ & $\begin{array}{l}\text { Cozy/ } \\
\text { Comfo } \\
\text { rtab1 } \\
\text { e2 }\end{array}$ & $\begin{array}{l}\text { Sentiment/ } \\
\text { romantic }\end{array}$ & $\begin{array}{c}\text { Cartoon/Dim/Beaut } \\
\text { iful/ Cold and } \\
\text { cheerless/Young } \\
\text { people/chaos/Euro } \\
\text { pean style } \\
\text { /Dilapidated/Life } \\
\text { /Christmas/grace/ } \\
\text { resource } \\
\text { utilization/ } \\
\text { Western } \\
\text { style/sense of } \\
\text { modernity/like/Bo } \\
\text { ring }\end{array}$ \\
\hline
\end{tabular}

The word frequency of the visual attractors in cultural and creative blocks is too many, only part of the content is simply intercepted. Based on the word frequency table of the visual attractors in cultural and creative blocks, such data can be obtained. The word frequency composition of the visual attractors in each cultural and creative block is also diverse, but the differences also exist, such as the highest word frequency of the visual attractors in Dayan Huaxiang, Lijiang, Yunnan Province. It is nostalgia. The highest word frequency of visual attraction of sculpture technology is nostalgia. The highest word frequency of visual attraction of architecture is nostalgia. The highest word frequency of visual attraction of street installation is nostalgia. The highest word frequency of visual attraction of wall brick is nostalgia. The highest word frequency of visual attraction of commodity color painting is general. The highest word frequency of visual attraction of roadway is nostalgia. The highest word frequency of visual attraction of leisure activities is nostalgia. The highest frequency of words is joyful, and the highest frequency of words for the visual attraction of signboards is nostalgia; for example, the frequency of words in Shenzhen Overseas Chinese town will be different, and the highest frequency in turn is literature and art, creativity, general, bright, general, art, literature and art, ease and special.

According to "Table VII", it can be seen that many words of word frequency in cultural and creative blocks may have different expressions, but after induction, the coincidence rate is very high. The high frequency word frequency of the visual attraction of 22 cultural and creative blocks is mainly composed of nostalgia, creativity and literature and art, while the high frequency word frequency of the visual attraction of only a few cultural and creative blocks is different from that of most cultural and creative blocks.

\section{CONCLUSION}

Through the collation and analysis of the image word frequency of 22 cultural and creative blocks, we can get a conclusion that nostalgia is an indispensable theme no matter what type of cultural and creative blocks. With the change of China's era, social culture is also changing imperceptibly: many old cities in the city have undergone major transformation, and some old places or old buildings with many years of history or traditional culture are gradually

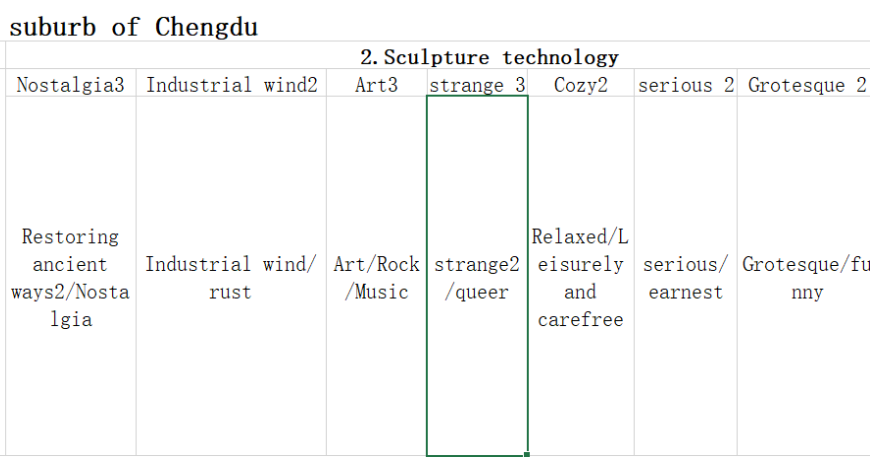

disappearing [34]. But on the other hand, with the disappearance of these traditional cultural representatives, people are looking back to these things with nostalgic culture, so there are more and more archaize and retro phenomenon.

Taking 22 cultural and creative districts as examples, this paper proves that at present, the main internal component of most cultural and creative districts in China is nostalgia, supplemented by other cultural and creative districts.

The general secretary also pointed out in face-to-face discussions with the masses of all ethnic groups and grassroots leaders on the development and construction: "we can keep the green mountains and green waters, and remember the homesickness." In the sustainable development of tourism, nostalgia will also be an important trend in the future. Nowadays, the tourism market, not only cultural and creative blocks tends to be nostalgic, but also more tourism products or scenic spots in other aspects begin to attach importance to the important role of nostalgia.

According to the needs of tourists and the exploration of tourists' psychological process, tourism designers show a kind of "old atmosphere" when designing tourism products, and make use of traditional cultural elements or old objects to create an "old charm" and stimulate tourists' feelings [35].The same is true for cultural and creative blocks. In order to attract more tourists, a sense of vicissitudes and history is created in the color matching of visual attractions or objects. It can be seen that nostalgia will still be a mainstream for a long time in the future. On the road of sustainable development of tourism, it will contribute an unlimited power to the tourism industry.

\section{REFERENCES}

[1] Chen Hanxin, Chinese culture creative industry: Developmental actuality and prospect,Economic Geography, vol. 28, pp. 728-733, September, 2008

[2] Zhengbin and Liu Jiaming and Yang Zhaoping, Study on Creative Industrial Parks of Cultural Tourism Based on"One-stop Experience", Tourism Tribune,vol. 23,pp. 49-53, September,2008

[3] Chu Jinfeng A Study on Spatial Difference of the Creative Industrial Zones in Shanghai, Human Geography, vol.24,pp. 23-28, April,2009

[4] Wang Yi and Liao Zhuoxian,Development and Construction Path of Hunan Cultural and Creative Industry Park Economic Geography, vol.39, pp. 215-223 February ,2019 
[30] Noth, W. Handbook of semiotics. Indianapolis: Indiana University Press, 1990

[31] Patton, M. Q. Qualitative evaluation and research methods. Newbury Park, CA: Sage, 1990

[32] Gobo, G. Re-conceptualizing generalization: old issues in a new frame. In P. Alasuutari, L. Bickman, \& J. Brannen (Eds.), The Sage handbook of social research methods (pp. 193e213). London: Sage, 2008

[33] Balch, G. Review. Journal of Marketing Research, 19(1), 162163,1982

[34] Li Fan, The Phenomena of Urban Nostalgia Under the Background of Globalization and Its Geographical Perspective, Human Geography ,vol.27,pp.28-33, June,2012

[35] Xiong Jianfeng, A Nostalgic Tourist Resolution, Tourism Science, vol.26, pp. 30-37, October, 2012.

[10] Rose, G. Visual methodologies: An introduction to the interpretation of visual materials. London: Sage. 2003

[11] Russell, D. B., \& Ison, R. L. The research-development relationship in rural communities: an opportunity for contextual science. In R. L. Ison, \& D. B. Russell (Eds.), Agricultural extension and rural development: Breaking out of traditions,pp. 10-31,Cambridge: Cambridge University Press. 2000

[12] Paradis, T. W. The political economy of theme development in small urban places: the case of Roswell, New Mexico. Tourism Geographies, 4(1), 22-43,2002

[13] Crouch, D., \& Lubbren, N. (Eds.). Visual culture and tourism. New York: Berg,2006

[14] Hunter, W. C. A typology of photographic representations for tourism. Tourism Management, 29(2), 354-365,2008

[15] William Cannon Hunter,China's Chairman Mao: A visual analysis of Hunan Province online destination image, Tourism Management,pp.101-111,2013

[16] Jenkins, O. H. Photography and travel brochures: the circle of representation. Tourism Geographies, 5(3), 305-328.2003

[17] Govers, R., Go, F. M., \& Kumar, K. Virtual destination image: a new measurement approach. Annals of Tourism Research, 34(4), 977997,2007

[18] Stepchenkova, S., \& Morrison, A. The destination image of Russia: from the online induced perspective. Tourism Management, 27(5), 943-956, (2006).

[19] Choi, S., Lehto, X. Y., \& Morrison, A. M. Destination image representation on the web: content analysis of Macau travel related websites. Tourism Management, 28(1), 118-129.2007

[20] Prebensen, N. K. Exploring tourists' images of a distant destination. Tourism Management, 28(3), 747-756,2007

[21] Smith, A. Conceptualizing city image change: the 're-imaging' of Barcelona. Tourism Geographies, 7(4), 398-423,2005

[22] Silver, I. Marketing authenticity in third world countries. Annals of Tourism Research, 20(2), 302-318,1993

[23] Billig, M. Banal nationalism. London: Sage.,2006

[24] Preiswerk, R., \& Perrot, D. Ethnocentrism and history: Africa, Asian and Indian America in Western textbooks. NY: NOK Publishers International, 1978

[25] Brown, R. H. The poststructural crisis in the social sciences: learning from James Joyce. In R. H. Brown (Ed.), Postmodern representations: Truth, power and mimesis in the human sciences and public culture, Urbana:University of Illinois Press, pp. 134-167,1995

[26] Hendry, J. Reclaiming culture: Indigenous people and selfrepresentation. NY: Palgrave Macmillan,2005

[27] Wolcott, H. F.Making a study "more ethnographic". In J. F. Maanen (Ed.), Representation in ethnography, London: Sage, pp. 79-111,1995

[28] Hollinshead, K. Representation. In J. Jafari (Ed.), Encyclopedia of tourism, NY: Routledge, pp. 501,2000

[29] Edwards, E. The tourist icon: four Australian postcards. Tourism in Focus, 6,pp. 4-5,1996 